\title{
Observations of dynamical behavior in a stochastic Wilson-Cowan population with plasticity
}

\author{
Jeremy Neuman ${ }^{1 *}$, Bert Kiewiet ${ }^{2}$, Jack D Cowan ${ }^{3}$, Wim van Drongelen ${ }^{4}$ \\ From Twenty Second Annual Computational Neuroscience Meeting: CNS*2013 \\ Paris, France. 13-18 July 2013
}

Understanding network connectivity and its role in brain activity is an arduous task. Complicating matters further is the introduction of synaptic plasticity rules. Observations using a mean-field perspective [1] are by their nature incomplete so, here, a stochastic model, which includes fluctuations, has been employed. This analysis shows that two types of network connections, driven by plasticity, exhibit oscillatory behavior signaled by a flipping between Up and Down states. Fluctuations in each state in both setups display power law-like avalanche distributions.

This study, employing a stochastic algorithm [2] used previously in a population-based model [3], introduces plasticity, according to a modified version of [4], into both an $\mathrm{E} \rightarrow \mathrm{E}$ and $\mathrm{I} \rightarrow \mathrm{E}$ network (Figure 1A). The former network includes plastic excitatory, anti-Hebbian synapses, connecting the populations, while the latter contains plastic inhibitory Hebbian synapses. Both networks incorporate a constant recurrent excitatory synapse. Dynamically, each network undergoes oscillations of relaxation type (Figure 1B) with fluctuations whose avalanche distributions look like power laws (Figure 1C).

\section{Conclusions}

Understanding the dynamics of plasticity-driven neural networks is vital. Here, it was shown that a stochastic Wilson-Cowan population connected to an exterior
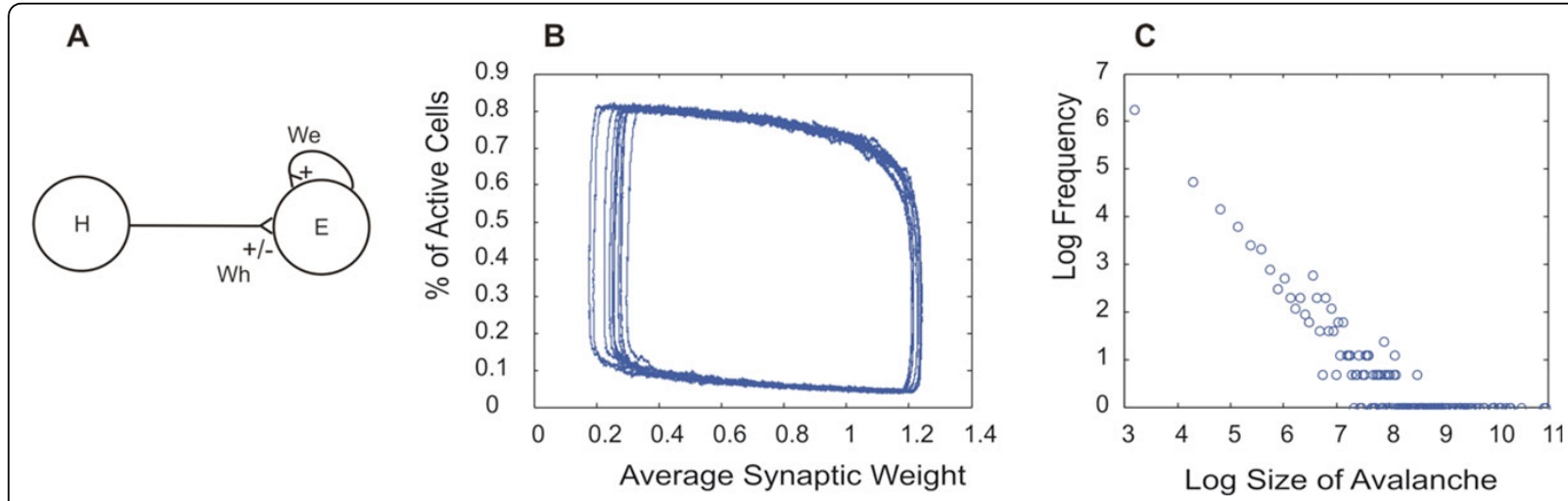

Figure 1 Network configuration with two populations. (A) Diagram of the connection. If $\mathrm{H}$ is an excitatory population, synapse Wh has anti-Hebbian plasticity. If $\mathrm{H}$ represents an inhibitory population, the synapse has Hebbian plasticity. (B) Phase plot of activity of $\mathrm{E}$ versus the strength of Wh in the scenario where $\mathrm{H}$ is an inhibitory network. (C) The avalanche distribution of the Up state in panel (B).

\footnotetext{
* Correspondence: jneuman@uchicago.edu

'Dept. of Physics, University of Chicago, Chicago, IL 60637, USA

Full list of author information is available at the end of the article
} 
population can naturally exhibit relaxation oscillations. This result with its power law avalanche statistics is a potential sign of self-organized criticality.

\section{Acknowledgements}

This work was supported by the Dr. Ralph and Marian Falk Medical Research Trust Fund.

\section{Author details}

${ }^{1}$ Dept. of Physics, University of Chicago, Chicago, IL 60637, USA. ${ }^{2}$ Dept. of Applied Mathematics, University of Twente, 7500 AE Enschede, Netherlands. ${ }^{3}$ Dept. of Mathematics, University of Chicago, Chicago, IL 60637, USA. ${ }^{4}$ Dept. of Pediatrics, University of Chicago, Chicago, IL 60637, USA.

\section{Published: 8 July 2013}

\section{References}

1. Wilson H, Cowan J: Excitatory and Inhibitory Interactions in Localized Populations of Model Neurons. Biophys J 1972, 12:1-22.

2. Gillespie D: Exact stochastic simulation of coupled chemical reactions. J Phys Chem 1977, , 81: 2340-2361.

3. Benayoun M, Cowan J, van Drongelen W, Wallace E: Avalanches in a Stochastic Model of Spiking Neurons. PLoS Comput Biol 2010, 6:e1000846.

4. Vogels T, Sprekeler H, Zenke F, Clopath C, Gerstner W: Inhibitory Plasticity Balances Excitation and Inhibition in Sensory Pathways and Memory Networks. Science 2011, 334: 664-666.

\section{Submit your next manuscript to BioMed Central} and take full advantage of:

- Convenient online submission

- Thorough peer review

- No space constraints or color figure charges

- Immediate publication on acceptance

- Inclusion in PubMed, CAS, Scopus and Google Scholar

- Research which is freely available for redistribution

Submit your manuscript at www.biomedcentral.com/submit 